\title{
Trends in the use of electrical cardioversion for atrial fibrillation: influence of major trials and guidelines on clinical practice
}

\author{
Josep M Alegret ${ }^{1 *}$, Xavier Viñolas², César Romero-Menor ${ }^{3}$, Silvia Pons ${ }^{4}$, Roger Villuendas ${ }^{5}$, Naiara Calvo ${ }^{6}$,
} Jordi Pérez-Rodon ${ }^{7}$, Xavier Sabaté ${ }^{8}$ and REVERCAT study investigators

\begin{abstract}
Background: The purpose of the present study was to assess the trends in the use of ECV following published studies that had compared rhythm and rate control strategies on atrial fibrillation (AF), and the recommendations included in the current clinical practice guidelines.

Methods: The REVERCAT is a population-based assessment of the use of electrical cardioversion (ECV) in treating persistent AF in Catalonia (Spain). The initial survey was conducted in 2003 and the follow-up in 2010.

Results: We observed a decrease of 9\% in the absolute numbers of ECV performed (436 in 2003 vs. 397 in 2010). This is equivalent to $27 \%$ when considering population increases over this period. The patients treated with ECV in 2010 were younger, had a lower prevalence of previous embolism, a higher prevalence of diabetes, and increased body weight. Underlying heart disease factors indicated, in 2010, a higher proportion of NYHA $\geq 1$ and left ventricular ejection fraction $<30 \%$. We observed a reduction in the number of ECV performed in 16 of the 27 (67\%) participating hospitals. However, there was an increase of $14 \%$ in the number of procedures performed in tertiary hospitals, and was related to the increasing use of ECV as a bridge to AF ablation. Considering the initial number of patients treated with ECV, the rate of sinus rhythm at 3 months was almost unchanged (58\% in 2003 vs. 57\% in 2010; $p=0.9$ ) despite the greater use of biphasic energy in 2010 and a similar prescription of anti-arrhythmic drugs.

Conclusions: Although we observed a decrease in the number of ECVs performed over the 7 year period between the two studies, this technique remains a common option for treating patients with persistent AF. The change in the characteristics of candidate patients did not translate into better outcomes.
\end{abstract}

Keywords: Atrial fibrillation, Electrical cardioversion, Rhythm control, Rate control, Follow-up

\section{Background}

The REVERCAT study (REgistre sobre la cardioVERSió elèctrica a CATalunya; Registry of Electrical Cardioversion in Catalonia) is a multi-center study involving 27 participating hospitals. The recording of characteristics of electrical cardioversion (ECV) was intended to evaluate the use of the technique in patients with atrial fibrillation (AF) in current clinical practice in Catalonia (Spain). The initial study was conducted at the start of

\footnotetext{
* Correspondence: txalegret@hotmail.com

'Secció de Cardiologia, Hospital Universitari de Sant Joan, Institut d'Investigacions Sanitàries Pere Virgili, Universitat Rovira i Virgili, C/Dr. Laporte, s/n, Reus 43205, Spain

Full list of author information is available at the end of the article
}

2003. The current re-evaluation was conducted early in 2010 and, over these past 7 years, there have been a few studies published, and subsequent guidelines generated, which described the lack of a clear benefit of rhythm control vs. rate control strategies in patients with AF [1-3]. The purpose of the present study was to compare the frequency and characteristics of patients treated with ECV between the years 2003 and 2010; the objective being to assess the impact of major clinical trials and recommendations included in the current clinical practice guidelines.

\section{Methods}

The REVERCAT study was set-up to record, prospectively, all patients with persistent AF who were 
considered candidates for ECV. There were 27 participating hospitals which are representative of the whole of Catalonia (an Autonomous Community in NE Spain) (Table 1).

The area of Catalonia is $31,930 \mathrm{~km}^{2}$ and the population was 6,506,000 inhabitants in 2003 and 7,512,000 inhabitants in 2010, all of whom have the right to health-care provision under the publicly-funded National Health Service. The hospitals participating in the present study attend to approximately $90 \%$ of this population. The initial registry was set-up between $1^{\text {st }}$ February and $30^{\text {th }}$ October 2003 . The present study was conducted between $1^{\text {st }}$ February and $30^{\text {th }}$ October 2010, the purpose being to assess the changes in the use of ECV in clinical practice in Catalonia. The patients included in the study to have ECV applied were all those who met the criteria of being $\geq 18$ years of age, with AF

\begin{tabular}{ll}
$\begin{array}{l}\text { Table } \mathbf{1} \text { List of investigators and centers participating in } \\
\text { the REVERCAT study }\end{array}$ \\
\hline $\begin{array}{ll}\text { Clinical Investigator } \\
\text { X }\end{array}$ & Affiliation \\
\hline X Sabaté & H.U. de Bellvitge, Hospitalet de Llobregat \\
R Serrat & H del Mar \\
A Sualís & H de Mataró \\
F Planas & H. de Badalona \\
G Vazquez & H. Comarcal de la Selva, Blanes \\
J Escudero & H Mútua de Terrassa \\
X Abardia/C Barberà & Clínica Ponent, Lleida \\
L Guillamon & H. Parc Taulí, Sabadell \\
L Mont/N Calvo & H. Clínic, Barcelona \\
J Sadurní & H. General de Vic \\
S Pons & H de Barcelona \\
A Descalzi & H. Comarcal Alt Penedés, Vilafranca del Penedés \\
N Batalla & H. Sagrat Cor, Barcelona \\
E Sanz/S Serrano & H.U. Joan XXIII, Tarragona \\
J Pérez-Rodon & H.G.U. Vall d' Hebrón, Barcelona \\
E Rodríguez-Font & H. Sta Creu i Sant Pau, Barcelona \\
F Freire & H. de Palamós, Palamós \\
M Vilaseca & H de Calella, Calella \\
C Romero & H. Sant Boi de Llobregat \\
I Duran & H.U. Sant Joan de Reus \\
J Tomàs & H.U. Arnau de Vilanova, Lleida \\
I Lechuga & H. Verge de la Cinta, Tortosa \\
R Villuendas & H. Germans Trias i Pujol, Badalona \\
A Jaber & H. de Terrassa \\
I Romeo & H. d'lgualada \\
R Canals & Paz
\end{tabular}

${ }^{a}$ Collaborators in Pubmed. duration $>7$ days, and with no precipitating conditions including hyperthyroidism, fever, cardiac surgery and pericarditis. Successful ECV was considered when sinus rhythm (SR) was achieved, and excluded patients with immediate relapse. A clinical and ECG follow-up was performed at 3 months post-ECV. Patients were considered to have maintained SR at 3 months if there had not been a relapse of persistent AF and, as well, the ECG at 3 months of follow-up showed SR. The information recorded included clinical data, treatment, echocardiography data, and procedure variables. We compared all these variables in the two surveys conducted 7 years apart. The principal investigator in each hospital was the same in both surveys in 21 of the 27 participating hospitals.

The study received approval from the Institutional Review Boards (Clinical Ethics Committee) of each participating hospital on the understanding that the data were coded on entry into the registry and that patient privacy was respected. Written informed consent was obtained from the patient for publication of this report.

\section{Statistical analyses}

Qualitative variables are expressed in percentages, and the differences assessed using the chi-squared test. Quantitative variables are presented as means \pm standard deviation (SD) and the differences between means evaluated using the Student $t$-test. Statistical significance was accepted at $\mathrm{p}$ values $<0.05$. All analyses were performed with the SPSS statistical software package (version 18).

\section{Results}

There were 397 ECVs performed in 2010 compared to 436 in 2003. These were consecutive patients meeting the inclusion criteria and having ECV performed over the same period of the year-of-study (February to October). This represents a 9\% reduction in the number of procedures which, when taking into account the increase in the catchment population between 2003 and 2010, represents a reduction of $27 \%$.

The clinical characteristics are summarized in Table 2. The patients treated with ECV in 2010 had a lower mean age, a lower prevalence of prior embolism, a higher prevalence of diabetes and a higher mean body weight compared to those treated with ECV in 2003.

With respect to the underlying heart disease, in 2010 we observed a higher proportion of NYHA $\geq$ II, lower mean ejection fraction, and a higher prevalence of $\mathrm{EF}<30 \%$ than in 2003.

There was a reduction in the numbers of patients in whom ECV was applied in 16 of 27 (67\%) participating hospitals. However, the distributions of the treatment indicated a higher number of ECV procedures in tertiary-care hospitals (mainly university-associated) 
Table 2 Comparisons of the clinical and echocardiographic characteristics of patients included in the two surveys (2003 versus 2010) of electrical cardioversion

\begin{tabular}{|c|c|c|c|}
\hline \multirow[t]{2}{*}{ Characteristic } & \multirow{2}{*}{$\begin{array}{l}2003 \text { survey } \\
(n=436)\end{array}$} & \multirow{2}{*}{$\begin{array}{l}2010 \text { survey } \\
(\mathrm{n}=397) \\
\text { Mean } \pm \text { SD } \\
\text { or } n(\%)\end{array}$} & \multirow[t]{2}{*}{$\mathbf{P}$} \\
\hline & & & \\
\hline Age; years & $65 \pm 11$ & $64 \pm 11$ & 0.03 \\
\hline Age; $>70$ years & $170(39)$ & $119(30)$ & 0.008 \\
\hline Male gender & $296(68)$ & $285(72)$ & 0.19 \\
\hline Weight; kg & $78.2 \pm 13$ & $80.9 \pm 14$ & 0.01 \\
\hline Height; cm & $167 \pm 9$ & $168 \pm 9$ & 0.14 \\
\hline Body surface area; $\mathrm{m}^{2}$ & $1.86 \pm 0.19$ & $1.90 \pm 0.19$ & 0.006 \\
\hline Hypertension & $222(51)$ & $222(56)$ & 0.14 \\
\hline Diabetes mellitus & $57(13)$ & $75(19)$ & 0.04 \\
\hline Previous embolism & $46(12)$ & $29(7)$ & 0.02 \\
\hline NYHA Class $\geq \|$ & $135(31)$ & $175(44)$ & 0.0001 \\
\hline Left atrial size & $45.4 \pm 6.3$ & $45.4 \pm 6.8$ & 0.95 \\
\hline $\begin{array}{l}\text { Left atrial dilatation } \\
(>50 \mathrm{~mm})\end{array}$ & $61(14)$ & $67(17)$ & 0.42 \\
\hline $\begin{array}{l}\text { Left ventricular } \\
\text { hypertrophy }\end{array}$ & $113(26)$ & $119(30)$ & 0.21 \\
\hline LVEF (\%) & $58 \pm 14$ & $56 \pm 14$ & 0.02 \\
\hline LVEF <30\% & $8(2)$ & $19(5)$ & 0.05 \\
\hline $\begin{array}{l}\text { Previous electrical } \\
\text { cardioversion }\end{array}$ & $65(15)$ & $87(22)$ & 0.009 \\
\hline Duration of $A F>1$ year & $48(11)$ & $59(15)$ & 0.35 \\
\hline Anti-arrhythmic drugs & $327(78)$ & $296(76)$ & 0.39 \\
\hline Amiodarone: & $268(64)$ & $247(62)$ & \\
\hline lc: & 39 (9) & $32(9)$ & \\
\hline Sotalol: & $9(2)$ & $5(1)$ & \\
\hline Others: & $11(3)$ & $12(3)$ & \\
\hline ACE inhibitor/ARB & $197(45)$ & $197(50)$ & 0.12 \\
\hline
\end{tabular}

${ }^{*} A F$ : atrial fibrillation; $L V E F$ : left ventricular ejection fraction; Ic: flecainide, propafenone; $A C E$ : angiotensin-converting enzyme; $A R B$ : angiotensin receptor blockers.

compared to district general hospitals between 2003 and 2010. In 2003 the district hospitals accounted for 57\% of procedures compared to $43 \%$ in the tertiary hospitals. In 2010 the district hospitals performed $47 \%$ of the procedures compared to $53 \%$ in tertiary hospitals $(\mathrm{p}=0.004)$. Between 2003 and 2010, we observed an absolute decrease of $23 \%(\mathrm{p}=0.004)$ in the number of ECVs performed in district hospitals (247 in 2003 vs. 189 in 2010). Conversely, there was an absolute increase in the use of ECV in tertiary hospitals of $14 \%(\mathrm{p}=0.004)$ in 2010 (189 in 2003 vs. 208 in 2010). There were 7 patients in 2003 in whom ECV was applied as a bridge to AF ablation. In 2010 the number increased to 36; 3 centers performing AF ablations in 2003, and 5 centers in 2010. Overall, the numbers of AF ablations performed in the two periods of the study were 30 in 2003 and 129 in 2010.

The ECV success rates were similar in 2003 and 2010 ( $86 \%$ in 2003 vs. $89 \%$ in $2010 ; \mathrm{p}=0.21$ ), despite the more frequent use of biphasic energy in 2010 (16\% in 2003 vs. $88 \%$ in 2010; $\mathrm{p}=0.0001$ ) (Table 3).

The use of anti-arrhythmic drugs pre-ECV and at discharge from hospital was also similar in both surveys (preECV $73 \%$ in 2003 vs. $68 \%$ in 2010; $\mathrm{p}=0.26$; at discharge $78 \%$ in 2003 vs. $76 \%$ in 2010; $\mathrm{p}=0.39$ ). Amiodarone was the preferred drug in both studies. It was used in $64 \%$ of patients in $2003 v$ s. $62 \%$ of patients in $2010(\mathrm{p}=0.62)$, independently of underlying left ventricular ejection fraction. Dronedarone was not available in Spain until the end of the 2010 study.

With respect to anticoagulation treatment, the conventional use of coumarins at least 3 weeks pre- and 1 month post-ECV was the most common pattern (2003 $59 \%$ vs. $201061 \%$; $=0.75$ ). The rate of patients requiring chronic anticoagulant therapy prior to the decision to perform ECV was similar (27\% in 2003 vs. $30 \%$ in 2010; $\mathrm{p}=0.67$ ), whereas the use of transesophageal echocardiography with short patterns of anticoagulation (5\% in 2003 vs. $7 \%$ in 2010; $\mathrm{p}=0.65)$ and other patterns $(9 \%$ in 2003 vs. $2 \%$ in $2010, \mathrm{p}=0.28$ ) were very low in both surveys.

The rate of SR was similar in both surveys at 3 months of follow-up (67\% in 2003 vs. $64 \%$ in 2010; $p=0.21$ ). If we considered the patients with and without antiarrhythmic drugs at discharge from hospital, the rates of SR at 3 months were also similar. The patients receiving anti-arrhythmic medications in 2003 accounted for $70 \%$ of the total compared to $68 \%$ in $2010(\mathrm{p}=0.30)$. Patients

Table 3 Electrical cardioversion procedure characteristics in both surveys (2003 versus 2010)

\begin{tabular}{|c|c|c|c|}
\hline \multirow[t]{2}{*}{ Characteristic } & \multirow{2}{*}{$\begin{array}{l}2003 \text { survey } \\
(n=436)\end{array}$} & \multirow{2}{*}{$\begin{array}{l}\begin{array}{l}2010 \text { survey } \\
(\mathrm{n}=397)\end{array} \\
\text { Mean } \pm \text { SD } \\
\text { or } n(\%)\end{array}$} & \multirow[t]{2}{*}{$\mathbf{P}$} \\
\hline & & & \\
\hline Use of biphasic energy & $70(16)$ & $349(88)$ & $<0.001$ \\
\hline Successful ECV (overall) & $374(86)$ & $355(89)$ & 0.21 \\
\hline - Monophasic energy & $313(85)$ & $42(87)$ & 0.69 \\
\hline - Biphasic energy & $61(89)$ & $313(90)$ & 0.90 \\
\hline Number of shocks (overall) & $1.73 \pm 0.9$ & $1.5 \pm 0.9$ & 0.0001 \\
\hline - Monophasic shocks & $1.76 \pm 0.9$ & $1.70 \pm 0.83$ & 0.90 \\
\hline - Biphasic shocks & $1.61 \pm 0.86$ & $1.45 \pm 0.78$ & 0.07 \\
\hline Energy delivered (overall) (J) & $239 \pm 90$ & $165 \pm 63$ & 0.0001 \\
\hline - Monophasic shocks & $253 \pm 77$ & $234 \pm 81$ & 0.11 \\
\hline - Biphasic shocks & $166 \pm 95$ & $154 \pm 51$ & 0.48 \\
\hline
\end{tabular}

${ }^{*} E C V$ : electrical cardioversion; J: Joules. 
not receiving anti-arrhythmic medications in 2003 accounted for $58 \%$ of the total compared to $55 \%$ in 2010 $(\mathrm{p}=0.59)$. Of those treated with ECV, the rate of patients in whom the SR was restored and maintained at 3 months was almost unchanged in the two periods of the study (58\% in 2003 vs. $57 \%$ in 2010; p = 0.9).

\section{Discussion}

To the best of our knowledge this is the first populationbased study that analyzed the treatment of AF over time, specifically the use of ECV. Also, this was an opportunity to observe the impact in clinical practice of new evidence reflected in guideline recommendations. We observed that between 2003 and 2010 there was a reduction in the number of ECVs performed and a change in the characteristics of patients treated i.e. this finding may be related to a lower use of the rhythm control strategy compared to rate control in the population with the current characteristics. However, ECV continues to be used frequently in clinical practice.

The AFFIRM and RACE trials [1,2] demonstrated no differences in terms of morbido-mortality when comparing rate $v s$. rhythm control strategies in patients with AF. Also the AF-CHF trial [4], focusing on patients with heart failure or left ventricular dysfunction, observed no difference in cardiovascular mortality. Prior to this evidence, it was accepted in clinical practice that the relief of symptoms as well as prevention of embolism and avoidance of cardiomyopathy (theoretically adding to the maintenance of SR) could be reasons for restoration of $\mathrm{SR}$. These consensus opinions are reflected in the guidelines from the ESC/AHA/ACC 2001 [5]. Subsequent to these publications, the concept became accepted that anticoagulation should not be stopped despite the restoration of SR in patients with criteria for anticoagulation. Thus, in the $2006 \mathrm{ESC} / \mathrm{AHA} / \mathrm{ACC}$ guidelines, the avoidance of long-term anticoagulation was not considered a reason for ECV [3]. The recent ESC 2010 guidelines [6] were published in the course of the conduct of the present study, as were the ACCF/AHA/HRS 2011 guidelines [7] which were published soon after the study's completion. These guidelines support anticoagulation maintenance (if the patient fulfills the criteria for anticoagulation) despite the patient achieving SR. Thus, guidelines limit the recommendations for ECV to patients with clear symptoms related to AF, without any intention to reduce morbido-mortality. Theoretically, this would imply a reduction in the number of ECVs performed. However, there is scant information regarding the influence of these guidelines on the use of ECV [8] and, perhaps more importantly, the characteristics of patients who are candidates for treatment with ECV. Our initial survey was begun in early 2003, a short time after the publication of the AFFIRM and RACE studies in December 2002, the findings of which are consistent with our findings in 2010. Although we observed a considerable decrease in the number of ECVs performed, this technique remains a common option for treating patients with AF. This may be related to the impression that, when the data from these trials are analyzed according to the patient's actual rhythm, the benefit of SR over AF becomes apparent [9]. A more profound analysis of AFFIRM study reveals several limitations that preclude the assumption that attempting to restore SR is not worthwhile i.e. the study had a low percentage of SR patients in the rhythm control group, low efficacy and increased risk of death of AAD, a high percentage of SR patients in the rate control group, lower use of betablockers in rhythm control group, and exclusion of patients with severe symptoms who would, potentially, most benefit from SR. Strictly, the study should not be interpreted as a comparison of SR $v s$. AF and, indeed, may reflect the ineffectiveness of the rhythm control methods used.

From our results we may deduce a change in the indications for ECV. Current patients are more symptomatic for heart failure, and with higher disease burden. We also noted that in the 2003 survey the patients were less symptomatic for heart failure, were older and with higher prevalence of previous embolism. This would suggest that, currently, the avoidance of long-term anticoagulation is not considered an indication for a rhythm control strategy in slightly symptomatic patients with criteria for anticoagulation. Although other factors may be contributing to these findings, the suggestion is that such publications may have had a significant influence on our standard clinical practice.

We note a reluctance towards the use of transesophageal echocardiogram (TEE) in the ECV procedure in both of our surveys that had been conducted 7 years apart. The publication of the ACUTE study [10] in 2001 negated the expectations that TEE could reduce embolisms and complications related to anticoagulation, as well as improve the efficacy of ECV because of the shorter time-lapse between the indication and the ECV. Both of our evaluations reflect the few occasions in which this technique may be useful in standard clinical practice. Conversely, we observed almost a complete substitution of monophasic energy (the more frequent option in 2003) for biphasic energy which was used in 2010, and which had been recommended in the 2006 guidelines. The use of biphasic source results in fewer skin lesions and greater rate of reversion to SR for the same amount of energy administered $[11,12]$. Also, maximum biphasic energy shock is useful, especially in patients with greater body surface area [13]. The slightly higher efficacy of ECV in our $2^{\text {nd }}$ survey of 2010 would be attributable to the use of biphasic energy. However, 
the more frequent use of biphasic energy and the change in patients' characteristics did not result in a higher rate of SR at 3 months of follow-up. Biphasic energy could benefit a patient with a profile of higher probability of AF relapse due to higher body mass index [14]. The use of anti-arrhythmic drugs was relatively high and similar in both surveys. Although its use was related to better rates of SR at 3 months of follow-up, its efficacy was relatively low. The introduction of new anti-arrhythmic drugs with higher efficacy and less adverse effects should help to improve these outcomes in the near future. Around half of the patients had been treated with ACE inhibitors/angiotensin receptor blockers (most of them for hypertension), without significant differences between both registries. The benefit of these drugs in the prophylaxis of AF relapse post-ECV has been clear in the published studies $[15,16]$ and this is reflected in the 2001 and 2006 ESC/AHA/ACC guidelines as well as the 2010 ESC guidelines, which do not recommend its use.

Of interest is the change in the number of ECVs performed in tertiary (referral) hospitals versus district (general) hospitals. Overall, in the district hospitals we observed a clear decrease in the number of ECVs performed while, in tertiary hospitals, there was an increase. The introduction of catheter ablation may explain these findings, with the use of ECV as a bridge to ablation. As mentioned earlier, this reflects the interest in the rhythm control strategy if there are appropriate therapeutic measures that impact on effective SR maintenance.

Our study has some limitations. One of them is the lack of information on the total number of patients with AF attended-to in our clinics. In consequence, we cannot strictly affirm that there has been a decrease in the proportion of patients treated with rhythm $v s$. rate control strategy. However, if we assess the increasing prevalence of AF $[17,18]$ related, above all, to aging we may deduce a decrease in the proportion of patients with AF treated with the rhythm control strategy; the proportion probably being higher than that indicated by the decrease in the number of ECV that we observed. In our population the mean age increased from 45.8 to 47 years and the number of people $>60$ years of age increased by $14 \%$ during this period. Another limitation of our study is the lack of information on symptoms strictly related to AF. Symptoms described in our study only related to heart failure. A scale of symptoms related to AF had been proposed in 2007 by the EHRA [19] and was included in the 2010 ESC guidelines. As such, it had not been available at the time of our first survey performed in 2003. However, we believe that the attempt to relieve, or improve, symptoms of heart failure may be considered when an ECV is indicated, as had been assessed in our survey.

\section{Conclusions}

In conclusion, we observed that ECV technique continues to be used widely as treatment for patients with AF; albeit applied to candidate patients with different characteristics.

\section{Abbreviations}

ECV: Electrical cardioversion; AF: Atrial fibrillation; SR: Sinus rhythm.

\section{Competing interest}

None

\section{Authors' contributions}

JMA: conception and design, analysis and interpretation of data, drafting the manuscript. XV: conception and design, acquisition of data. CR: conception and design, acquisition of data. SP: acquisition of data. RV: acquisition of data. NC: acquisition of data. JPR: acquisition of data. XS: acquisition of data. All authors read and approved the final manuscript.

\section{Funding}

This work was supported by the Catalan Society of Cardiology and funded, in part, by a non-directed grant from Sanofi-Aventis. The funding bodies had no involvement in the generation of the data, or their interpretation, or in the decision to publish.

\section{Author details}

${ }^{1}$ Secció de Cardiologia, Hospital Universitari de Sant Joan, Institut d'Investigacions Sanitàries Pere Virgili, Universitat Rovira i Virgili, C/Dr. Laporte, s/n, Reus 43205, Spain. ${ }^{2}$ Hospital de la Sta. Creu i Sant Pau, Barcelona, Spain. ${ }^{3}$ Parc Sanitari Sant Joan de Déu, Sant Boi de Llobregat, Spain. ${ }^{4}$ Hospital de Barcelona, Barcelona, Spain. ${ }^{5}$ Hospital Germans Trias i Pujol, Badalona, Spain. ${ }^{6}$ Hospital Clínic, Barcelona, Spain. ${ }^{7}$ Hospital Vall d'Hebron, Barcelona, Spain. ${ }^{8}$ Hospital de Bellvitge, Hospitalet de Llobregat, Spain.

Received: 14 February 2012 Accepted: 31 May 2012

Published: 18 June 2012

\section{References}

1. Wyse DG, Waldo AL, DiMarco JP, Domanski MJ, Rosenberg Y, Schron EB, Kellen JC, Greene HL, Mickel MC, Dalquist JE, Corley SD: Atrial Fibrillation Follow-up Investigation of Rhythm Management (AFFIRM) Investigators. A comparison of rate control and rhythm control in patients with atrial fibrillation. N Engl J Med 2002, 347:1825-1833.

2. Van Gelder IC, Hagens VE, Bosker HA, Kingma JH, Kamp O, Kingma T, Kamp O, Kingma T, Said SA, Darmanata JI, Timmermans AJ, Tijssen JG, Crijns HJ: Rate Control versus Electrical Cardioversion for Persistent Atrial Fibrillation Study Group. A comparison of rate control and rhythm control in patients with recurrent persistent atrial fibrillation. $N$ Engl J Med 2002, 347:1834-1840.

3. Fuster V, Ryden LE, Cannom DS, Crijns HJ, Curtis AB, Ellenbogen KA, Halperin JL, Le Heuzey JY, Kay GN, Lowe JE, Olsson SB, Prystowsky EN, Tamargo JL, Wann S: 2006 ACC/AHA/ESC guidelines for the management of patients with atrial fibrillation. Eur Heart J 2006, 27(16):1979-2030.

4. Talajic M, Khairy P, Levesque S, Connolly SJ, Dorian P, Dubuc M, Guerra PG, Hohnloser SH, Lee KL, Macle L, Nattel S, Pedersen OD, Stevenson LW, Thibault B, Waldo AL, Wyse DG, Roy D: Maintenance of sinus rhythm and survival in patients with heart failure and atrial fibrillation. J Am Coll Cardiol 2010, 55:1796-1802.

5. Fuster V, Rydén LE, Asinger RW, Cannom DS, Crijns HJ, Frye RL, Halperin JL, Kay GN, Klein WW, Lévy S, McNamara RL, Prystowsky EN, Wann LS, Wyse DG, Gibbons RJ, Antman EM, Alpert JS, Faxon DP, Fuster V, Gregoratos G, Hiratzka LF, Jacobs AK, Russell RO, Smith SC Jr, Klein WW, Alonso-Garcia A, Blomström-Lundqvist $C$, de Backer $G$, Flather M, Hradec J, Oto A, Parkhomenko A, Silber S, Torbicki A: ACC/AHA/ESC guidelines for the management of patients with atrial fibrillation: executive summary. Eur Heart J 2001, 22:1852-1923.

6. Camm AJ, Kirchhof P, Lip GY, Schotten U, Savelieva I, Ernst S, Van Gelder IC, Al-Attar N, Hindricks G, Prendergast B, Heidbuchel H, Alfieri O, Angelini A, Atar D, Colonna P, De Caterina R, De Sutter J, Goette A, Gorenek B, Heldal 
M, Hohloser SH, Kolh P, Le Heuzey JY, Ponikowski P, Rutten FH: Guidelines for the management of atrial fibrillation: the Task Force for the Management of Atrial Fibrillation of the European Society of Cardiology (ESC). Eur Heart J 2010, 31:2369-2429.

7. Wann $L S$, Curtis AB, January CT, Ellenbogen KA, Lowe JE, Estes NA 3rd, Page RL, Ezekowitz MD, Slotwiner DJ, Jackman WM, Stevenson WG, Tracy CM: 2011 ACCF/AHA/HRS focused update on the management of patients with atrial fibrillation (updating the 2006 guideline): a report of the American College of Cardiology Foundation/American Heart Association Task Force on Practice Guidelines. Hear Rhythm 2011, 8:157-176.

8. Mason PK, Wood MA, Lake D, DiMarco JP: Influence of the randomized trials, AFFIRM and RACE, on the management of atrial fibrillation in two university medical centers. Am J Cardiol 2005, 95:1248-1250.

9. Corley SD, Epstein AE, DiMarco JP, Domanski MJ, Geller N, Greene HL, Josephson RA, Kellen JC, Klein RC, Krahn AD, Mickel M, Mitchell LB, Nelson JD, Rosenberg Y, Schron E, Shemanski L, Waldo AL, Wyse DG, AFFIRM Investigators: Relationships between sinus rhythm, treatment, and survival in the Atrial Fibrillation Follow-Up Investigation of Rhythm Management (AFFIRM) Study. Circulation 2004, 109:1509-1513.

10. Klein AL, Grimm RA, Murray RD, Apperson-Hansen C, Asinger RW, Black IW, Davidoff R, Erbel R, Halperin JL, Orsinelli DA, Porter TR, Stoddard MF: Use of transesophageal echocardiography to guide cardioversion in patients with atrial fibrillation. N Engl J Med 2001, 344:1411-1420.

11. Koster RW, Dorian P, Chapman FW, Schmitt PW, O'Grady SG, Walker RG: A randomized trial comparing monophasic and biphasic waveform shocks for external cardioversion of atrial fibrillation. Am Heart J 2004, 147:e20.

12. Scholten M, Szili-Torok T, Klootwijk P, Jordaens L: Comparison of monophasic and biphasic shocks for transthoracic cardioversion of atrial fibrillation. Heart 2003, 89:1032-1034.

13. Alegret JM, Viñolas X, Sagristá J, Hernandez-Madrid A, Pérez L, Sabaté X, Mont L, Medina A, the REVERSE Study Investigators: Predictors of success and effect of biphasic energy on electrical cardioversion in patients with persistent atrial fibrillation. Europace 2007, 9:942-946.

14. Guglin M, Maradia K, Chen R, Curtis AB: Relation of obesity to recurrence rate and burden of atrial fibrillation. Am J Cardiol 2011, 107:579-582.

15. Ueng KC, Tsai TP, Yu WC, Tsai CF, Lin MC, Chan KC, Chen CY, Wu DJ, Lin CS, Chen SA: Use of enalapril to facilitate sinus rhythm maintenance after external cardioversion of long-standing persistent atrial fibrillation. Results of a prospective and controlled study. Eur Heart J 2003, 24:2090-2098

16. Tveit A, Seljeflot I, Grundvold I, Abdelnoor M, Smith P, Arnesen H: Effect of candesartan and various inflammatory markers on maintenance of sinus rhythm after electrical cardioversion for atrial fibrillation. Am J Cardiol 2007, 99:1544-1548.

17. Heeringa J, van der Kuip DA, Hofman A, Kors JA, van Herpen G, Stricker BH, Stijnen T, Lip GY, Witteman JC: Prevalence, incidence and lifetime risk of atrial fibrillation: the Rotterdam study. Eur Heart J 2006, 27:949-953.

18. Naccarelli GV, Varker H, Lin J, Schulman KL: Increasing prevalence of atrial fibrillation and flutter in the United States. Am J Cardiol 2009, 104:1534-1539.

19. Kirchhof P, Auricchio A, Bax J, Crijns H, Camm J, Diener HC, Goette A, Hindricks G, Hohnloser S, Kappenberger L, Kuck KH, Lip GY, Olsson B, Meinertz T, Priori S, Ravens U, Steinbeck G, Svernhage E, Tijssen J, Vincent A, Breithardt G: Outcome parameters for trials in atrial fibrillation: recommendations from a consensus conference organized by the German Atrial Fibrillation Competence NETwork and the European Heart Rhythm Association. Europace 2007, 9:1006-1023.

doi:10.1186/1471-2261-12-42

Cite this article as: Alegret et al:: Trends in the use of electrical cardioversion for atrial fibrillation: influence of major trials and guidelines on clinical practice. BMC Cardiovascular Disorders 2012 12:42.

\section{Submit your next manuscript to BioMed Central and take full advantage of:}

- Convenient online submission

- Thorough peer review

- No space constraints or color figure charges

- Immediate publication on acceptance

- Inclusion in PubMed, CAS, Scopus and Google Scholar

- Research which is freely available for redistribution

Submit your manuscript at www.biomedcentral.com/submit
C Biomed Central 